\title{
Review Article \\ The Mechanosensory Role of Primary Cilia in Vascular Hypertension
}

\author{
Surya M. Nauli, ${ }^{1}$ Xingjian Jin, ${ }^{1}$ and Beerend P. Hierck ${ }^{2}$ \\ ${ }^{1}$ Colleges of Medicine, Pharmacy and Pharmaceutical Sciences, The University of Toledo, Health Science Campus, HEB 274, \\ 3000 Arlington Avenue MS 1015, Toledo, OH 43614, USA \\ ${ }^{2}$ Department of Anatomy and Embryology, Leiden University Medical Center, P.O. Box 9600, 2300 RC Leiden, The Netherlands
}

Correspondence should be addressed to Surya M. Nauli, surya.nauli@utoledo.edu

Received 12 January 2011; Revised 22 March 2011; Accepted 9 April 2011

Academic Editor: Aaron S. Dumont

Copyright (C) 2011 Surya M. Nauli et al. This is an open access article distributed under the Creative Commons Attribution License, which permits unrestricted use, distribution, and reproduction in any medium, provided the original work is properly cited.

\begin{abstract}
Local regulation of vascular tone plays an important role in cardiovascular control of blood pressure. Aside from chemical or hormonal regulations, this local homeostasis is highly regulated by fluid-shear stress. It was previously unclear how vascular endothelial cells were able to sense fluid-shear stress. The cellular functions of mechanosensory cilia within vascular system have emerged recently. In particular, hypertension is insidious and remains a continuous problem that evolves during the course of polycystic kidney disease (PKD). The basic and clinical perspectives on primary cilia are discussed with regard to the pathogenesis of hypertension in PKD.
\end{abstract}

\section{Introduction}

The changes in blood vessel diameter serve as an important physiological regulator of blood flow. These changes, caused by contraction and relaxation of vascular smooth muscle, can be regulated centrally and locally. The central regulation of cardiovascular function is achieved through neuronal control through complex projections from central and peripheral neurons [1-3]. The density of this neuronal innervation on the adventitial layer of blood vessels varies from tissue to tissue and among different vascular structures [4-6]. Thus, local regulation of the blood vessel becomes important, especially in vessels with less abundant innervation or central regulation.

The mechanism involved in local regulation of blood vessels is termed autoregulation. It is required to achieve an immediate control of blood flow within a specific region in the tissue. Autoregulation is an effective and efficient way to control the amount of blood flow locally without altering the neighboring systems significantly [7]. In an isolated blood vessel, it has been shown that a sudden increase of transmural pressure reduces vessel diameter $[8-10]$, while a faster flow (higher shear stress) increases vessel diameter [9, 11-13]. All in all, the endothelial cells lining the lumen of the vessel have the ability to sense pressure and blood flow, and they are capable of transducing changes in mechanical forces into changes of vascular smooth muscle tone $[14,15]$. Thus, endothelial cells are able to decrease and increase arterial diameter by altering contraction and relaxation behaviors of smooth muscle cells in the artery.

Biophysically, mechanical forces in the blood vessel can be observed in the forms of stretch due to distention of surrounding muscle, cyclic strain due to the pulsatile nature of blood flow, compression due to differential pressure along the vascular system, pressure due to surface force of the systolic blood flow, and shear stress due to drag force generated by the blood flow (Table 1). These forms of mechanical forces may be physiologically impossible to differentiate in vivo because of the complex nature of the cardiovascular system [16]. Yet, these forces are known to be distinct from one another in cell culture or ex vivo studies [17-20]. Understanding the short-term and long-term effects of each individual force can therefore provide a better understanding of cardiovascular response, remodeling, adaptation, and disease. Of the mechanical forces mentioned above, we will discuss biophysical shear stress, which is probably one of the most studied biophysical forces. 
TABLE 1: Mechanical forces in the blood vessel.

\begin{tabular}{|c|c|}
\hline Types of force & Definitions \\
\hline Stretch & Distention force by surrounding muscle \\
\hline Cyclic strain & Pulsatile force by turbulent flow of blood \\
\hline Compression & $\begin{array}{l}\text { Contractile force by differential pressure in the } \\
\text { vessel }\end{array}$ \\
\hline Pressure & $\begin{array}{l}\text { Systolic force on intima surface by kinetic flow of } \\
\text { blood }\end{array}$ \\
\hline Shear stress & $\begin{array}{l}\text { Drag force along intima surface by kinetic flow of } \\
\text { blood }\end{array}$ \\
\hline
\end{tabular}

TABLe 2: Five distinct domains of a cilium.

\begin{tabular}{ll}
\hline Domains & Functions \\
\hline $\begin{array}{l}\text { Ciliary } \\
\text { membrane }\end{array}$ & $\begin{array}{l}\text { Localization of chemo- and mechanosensory } \\
\text { proteins } \\
\text { comple }\end{array}$ \\
$\begin{array}{l}\text { Axoneme } \\
\text { Ciliary tip }\end{array}$ & Localization of signaling molecules \\
Basal body & Localization of specialized signaling molecules \\
\hline
\end{tabular}

\section{Primary Cilia as Fluid-Shear Stress Sensors}

Primary cilia are usually classified as non-motile organelles with microtubules arranged in " $9+0$ " fashion. It has been suggested that, like the nucleus, mitochondria, golgi, and other intracellular organelles, a primary cilium can also be viewed as a separate entity within a cell (Table 2) [21]. A cilium can be studied as an organelle with five distinct domains: (1) the ciliary membrane, a specialized domain composed of a protein and with a lipid composition different from that of the rest of the plasma membrane; (2) the soluble compartment, also known as the matrix compartment or cilioplasm; (3) the axoneme, composed of nine pairs of microtubules with a highly structured transport motor cytoskeleton; (4) ciliary tip, housed specialized proteins whose roles are still to be explored further; (5) basal body, a "mature" or "mother" centriole from which the primary cilium is projected.

As micro-sensory compartments, cilia have functions that depend on mechano-proteins such as polycystin-1 and polycystin-2 (Figure 1). Thus, the overall functions of the sensory compartments depend on both functional and structural cilia proteins. Within a blood vessel, an abrupt increase in blood pressure or shear stress can be detected by these sensory proteins localized in the cilia $[16,24]$. With cilium functioning as a local regulatory mechanism, the extracellular fluid mechanics can then be transduced and translated into a complex of intracellular signaling, which in turn would activate eNOS - an endothelial enzyme that synthesizes nitric oxide (NO) gas. In particular, shear stressinduced calcium and $\mathrm{NO}$ signaling has been reported in many endothelial cells [25]. The released NO will diffuse from endothelial cells to the neighboring smooth muscle cells, thereby promoting vasodilation [26-28]. The overall

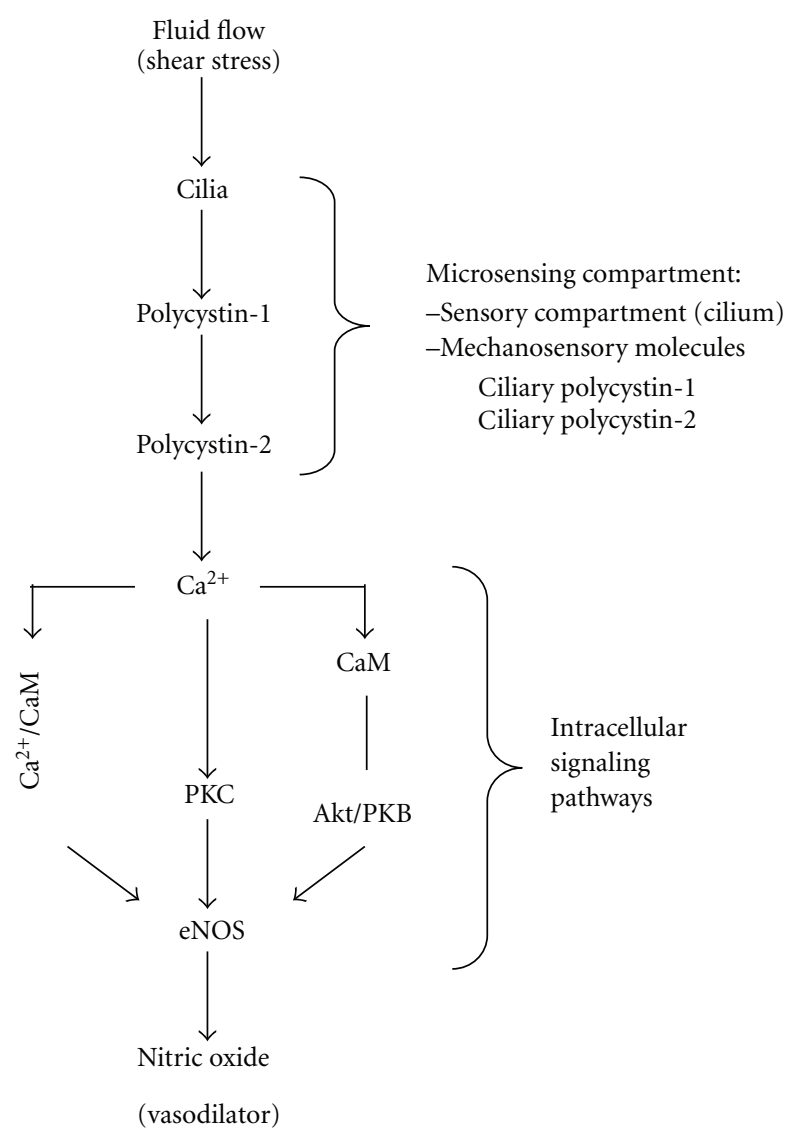

Figure 1: Mechanosensory cilia as microcompartments. Primary cilia are mechanosensory compartments that house many sensory proteins. Activation of these compartments through the sensory machineries will generate a cascade of various proteins activation, which results in nitric oxide production. CaM, calmodulin; PKC, calcium-dependent protein kinase; eNOS, endothelial nitric oxide synthase. Figure was adapted from [22].

effects of cilia function are thus to decrease total peripheral resistance, therefore lowering the blood pressure.

The presence of primary cilia in vascular endothelia has been reported in human arteries [29-31] and has been observed in cultured human cells $[16,32,33]$ and adult vascular system in vivo [34-38]. Of particular interest is a high level of polycystin expression in endothelial cells, which is required for the structural integrity of blood vessels [3944]. The expression of polycystins in human endothelial cilia provides a critical link between cilia and the vasculature $[16,32,33]$. Interestingly, the function of polycystin-1 as a mechanosensory molecule can be inactivated by proteolytic cleavage after exposure to high fluid-shear stress. This indicates that cilia function can also be regulated through modification of polycystin-1 via a high shear stress [24]. This further suggests that in patients with high blood pressure, that is, high shear stress, cilia would very likely be unable to sense minute changes in blood pressure, which might result in failure to autoregulate the local circulatory system. This might increase the possibility of localized blood vessel injuries, such as aneurysm, atherosclerosis, dissection, edema, hemorrhage, and vascular ectasia, among others. 

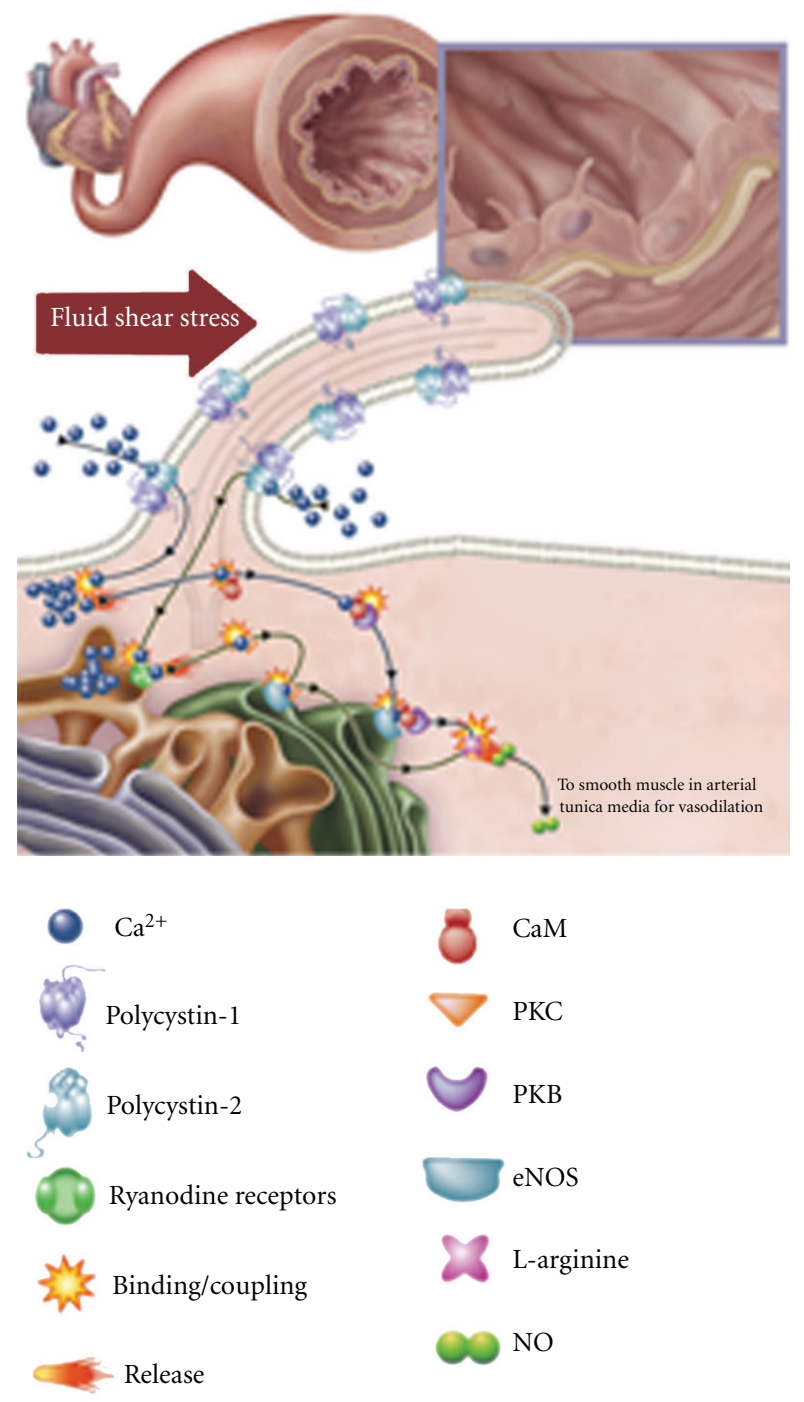

FIgUre 2: Mechanosensory cilia and nitric oxide production. The presence of cilia in vasculature plays an important role in the biochemical production of a potent vasodilator, nitric oxide (NO). The figure depicts the production of $\mathrm{NO}$ in an artery. Increases in blood pressure, which are translated to higher vascular shear stress, will be sensed by mechanosensory cilia. Bending or activation of the cilia involves mechanosensory polycystin- 1 and polycystin-2 complex and a cascade of biochemical synthesis of NO. The cascade will further involve extracellular calcium influx $\left(\mathrm{Ca}^{2+}\right)$, followed by activation of various calcium-dependent proteins, including calmodulin $(\mathrm{CaM})$ and protein kinase $\mathrm{C}(\mathrm{PKC}) . \mathrm{Akt} / \mathrm{PKB}, \mathrm{CaM}$, and $\mathrm{PKC}$ are important downstream molecular components to activate endothelial nitric oxide synthase (eNOS). This figure is reproduced with permission [23].

Throughout the cardiovascular system, patterns of fluid dynamics change considerably due to continuous vascular remodeling and patterning for microadaptation purposes $[43,45,46]$. The changes in the fluid dynamics generate differential biomechanical forces. These forces can initiate a complex of gene expressions $[5,7]$ which may also alter cilia function or structure in endothelial cells [24]. Consistent with this idea, it has been shown that not all vasculatures have cilia $[38,47,48]$. Only arteries with low fluid shear or high fluid turbulence have cilia, particularly longer, welldeveloped cilia. Because prolonged exposure to high fluidshear stress would induce cilia to disassemble [33], it is possible that cilia may not be needed to sense high shear stress. Rather, endothelial cells may have other mechanisms, such as glycocalyx, to sense much higher mechanical forces $[49,50]$.

\section{Converting Mechanical Sensor to NO Production}

To test the hypothesis that cilia are mechanosensitive organelles, endothelial cells without cilia were isolated and generated from $\mathrm{Tg} 737$ mouse. To further confirm that polycystin- 1 and -2 are sensory proteins in cilia, endothelial cells derived from mouse and human with polycystic kidney were used. Ciliary polycystin-1 and/or -2 are absent from the primary cilia in these cells. In $\mathrm{Tg} 737$ endothelial cells, polycystins are concentrated in the base of the primary cilia. Functional assays were carried out by challenging these cells with various magnitudes of fluid-shear stress $\left(0.5-50\right.$ dyne $\left./ \mathrm{cm}^{2}\right)$. While shear-induced cytosolic calcium increase is observed in normal endothelial cells, neither endothelial cells' isolated mutants nor diseased arteries exhibit this calcium response to shear stress $[16,24]$.

To validate cilia roles in fluid sensing, endothelial cells or arteries were subject to various mechanical stimulations (Table 1). The specificity of cilia function is confirmed when the shear-insensitive cells or arteries could respond to other mechanical stimulation. Most important is that PKD cells and arteries fail to produce nitric oxide $(\mathrm{NO})$ in response to fluid-shear stress.

To understand how ciliary polycystins are required to activate a biochemical cascade for $\mathrm{NO}$ production, various inhibitors were utilized to block the molecular functions [16]. Removing extracellular calcium with EGTA abolished both calcium and NO production in normal endothelial cells. Furthermore, L-NAME, an eNOS inhibitor, could block shear-induced NO biosynthesis, but not cytosolic calcium increase. This indicates that extracellular calcium influx is an upstream and prerequisite event. To explore calciumdependent mechanisms of NO production, the roles of protein kinase $\mathrm{C}$ (PKC) and calmodulin were investigated with calphostin C and W7, respectively. Possible downstream effectors, including Akt, PKB, and PI3K, were examined with pharmacological blockers Akt inhibitor II, LY-294,002, and wortmannin. Interestingly, only $\mathrm{Akt} / \mathrm{PKB}$, but not $\mathrm{PI} 3 \mathrm{~K}$, is involved in shear-induced NO production (Figure 2).

\section{Pathogenesis of Hypertension in PKD}

Polycystic kidney disease (PKD) is characterized by bilateral enlarged cystic kidneys, which have been associated with primary cilia dysfunction $[22,51,52]$. PKD is also characterized by various cardiovascular abnormalities. These abnormalities may include hypertension, cerebral and coronary 
TABle 3: Pathogenesis of hypertension in PKD.

\begin{tabular}{ll}
\hline Theories & Descriptions \\
\hline $\begin{array}{l}\text { Inherent cardiovascular } \\
\text { dysfunction (Figure 2) }\end{array}$ & $\begin{array}{l}\text { (ii) Endothelial dysfunction } \\
\text { (iii) Nitric oxide synthase dysfunction } \\
\text { (iv) Increased sympathetic nerve } \\
\text { activity }\end{array}$ \\
\hline & $\begin{array}{l}\text { (i) Compression of renal vasculature } \\
\text { releases renin } \\
\text { (ii) Renin converts angiotensinogen to } \\
\text { angiotensin }\end{array}$ \\
(iii) Activation of angiotensin receptor \\
will induce: \\
formation (Figure 3) \\
(1) Vasoconstriction \\
(2) Sensitivity to catecholamines \\
(3) Salt retention, and so forth.
\end{tabular}

artery aneurysms, mitral valve prolapse, aortic root dilation, dissection of the thoracic aorta, aneurysm formation in the abdominal aorta, vascular ectasia, and abnormal function of the microvascular bed [53-56]. Furthermore, the frequencies of cardiovascular complication in PKD patients are very high [57]. These include hypertension (78\%), cardiac valve disorders $(25 \%)$, and intracranial aneurysms (10\%).

Hypertension, in particular, has been a continual risk factor for other cardiovascular complications in PKD. Similar to cystogenesis, pathogenesis of hypertension in PKD has also been associated with primary cilia dysfunction. Within the context of clinical hypertension, there are two theories that could help describe the pathogenesis of hypertension in PKD (Table 3). The first theory points to inherent cardiovascular dysfunctions as the primary cause of hypertension; the second theory brings about the cystic kidney itself as the origin for hypertension.

4.1. Cardiovascular Dysfunction as a Primary Factor. In an observational study of 312 children with PKD, it is reported that high blood pressure promotes faster renal volume growth. PKD children with high blood pressure have faster renal growth than those with lower blood pressure. This suggests that hypertension is a risk factor independent from kidney function in PKD [58]. Consistent with this view, it has been suggested that high blood pressure can actually promote faster cyst growth $[59,60]$.

Of note is that hypertension occurs at a much earlier age in patients with $\mathrm{PKD}$ than in the general population [61]. The median age for hypertension in PKD patients is about 30 years, compared with a median age of $45-55$ years in patients with essential hypertension [62]. Hypertension occurs in children even before they are diagnosed with PKD [63-66] or before any substantial reduction in glomerular filtration rate is observed $[67,68]$.

To examine endothelial function in PKD, the plasma concentrations of vasodilator nitric oxide were measured in PKD patients and healthy controls. In this study, the plasma concentration of nitric oxide was reduced in

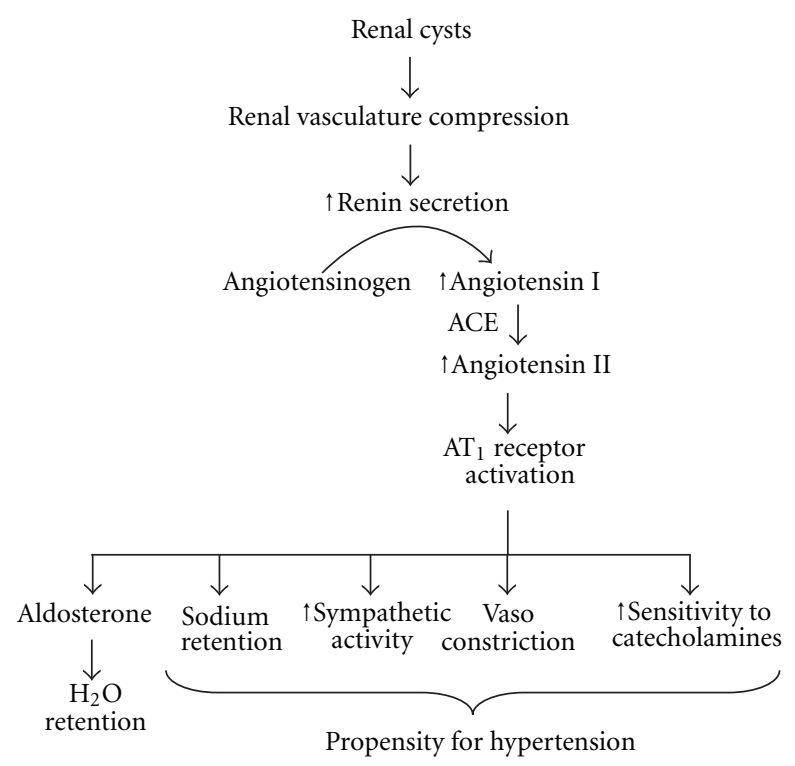

FIGURE 3: RAAS regulation in polycystic kidney disease. Renal cysts are thought to compress and disrupt the vascular network in the kidney. The kidney would then become ischemic, which would induce renin release from the juxtaglomerular apparatus. The increase in renin secretion could accelerate the conversion of angiotensinogen to angiotensin I, which is converted by angiotensin-converting enzyme (ACE) to angiotensin II. Activation of angiotensin receptor $\left(\mathrm{AT}_{1}\right)$ would initiate cascades of physiologi$\mathrm{cal}$ responses that would lead to hypertension.

PKD patients, confirming an association between PKD and endothelial dysfunction [69]. The endothelial dysfunction in PKD may thus be associated with abnormal cilia role in sensing fluid-shear stress and other downstream signaling mechanisms (Figure 2). To further substantiate the endothelial dysfunction in PKD, levels of ADMA (a marker of an inhibitor of nitric oxide synthase) were significantly increased in patients with early PKD compared to healthy age-matched individuals [70]. Although the significance of ADMA in PKD is not immediately understood, endothelia-dependent vasodilation offers substantial evidence which is too important to ignore.

Although ciliary therapy does not exist today, it is appealing and tempting to speculate the possibility of treatment for localized blood vessel injuries such as aneurysm, atherosclerosis, dissection, edema, hemorrhage, and vascular ectasia, among others in PKD. In particular, endothelium-dependent relaxation is impaired, and endothelial nitric oxide synthase activity is decreased in patients with PKD [71-73]. The endothelial dysfunction due to impaired release of NO in PKD patients becomes a crucial pathogenesis of hypertension. The imbalance in endothelium-derived vasoactive mediators might therefore need to be considered seriously in PKD patients $[74,75]$.

4.2. Cystic Kidney as a Primary Factor. It is believed that as renal cysts progress, the cysts will cause structural damage in the nephrons, which leads to distortion of the renal architecture (Figure 3). Such a distortion would compress the renal 
vasculature and attenuate the renal vessels, causing intrarenal ischemia and activation of the renin-angiotensin-aldosterone system (RAAS). Thus, as cysts enlarge, the RAAS is activated [76-78]. Not surprisingly, several studies have shown that the ACE-I (angiotensin-converting enzyme inhibitor) or the $\mathrm{ARB}$ (angiotensin receptor blocker) is effective in lowering blood pressure in PKD [79, 80].

Activation of the RAAS, which is well documented in the clinical course of the disease [81] and in PKD mouse models $[82,83]$, has been proposed to contribute to hypertension seen in PKD patients. RAAS activation has also been found in normotensive and hypertensive PKD patients, regardless of their blood pressure and renal function [84]. It is believed that the high level of circulating angiotensin II in PKD patients also contributes to the development of vascular hypertrophy, which is further implicated in vascular remodeling [85]. Changes in the vasculatures during the course of the PKD progression have therefore been observed in both human [86-90] and animal [91-95] studies.

It was also reported that the sympathetic nerve activity is increased in hypertensive patients with $\mathrm{PKD}$, regardless of renal function $[96,97]$. This suggests that sympathetic hyperactivity could contribute to the pathogenesis of hypertension in PKD. However, it is not immediately understood whether the sensitivity to sympathetic nerve activity is a secondary effect due to an increase in RAAS system. In a 3-year prospective randomized double-blind study, ACE-I ramipril and the beta-blocker metoprolol were both effective for use as a first-line therapy in hypertensive PKD patients [98]. However, it was suggested that aggressive blood pressure control with these agents is necessary in order for them to be beneficial for PKD patients [99]. Of apparent complexity is that angiotensin can stimulate the sympathetic nervous system and that sympathetic nerve activity can also stimulate RAAS $[100,101]$. At least in murine models of PKD, bilateral renal denervation could reduce cystic kidney size, cyst volume and most importantly, systolic blood pressure [102]. It is therefore very likely that sympathetic nerve activity would activate RAAS system, which would increase blood pressure.

Since cardiovascular abnormalities are thought to initiate from the cystic kidneys in PKD, there has been a great interest in studying the outcomes after renal transplantation in these individuals. Interestingly, renal transplant recipients with PKD still showed an increase in cardiovascular morbidity as seen in non-PKD transplant recipients [103]. In a different report of eleven transplant cases in hypertensive PKD, only six patients showed improved blood pressure after transplantation [104]. Improved blood pressure was defined as the ability to reduce antihypertensive drug treatment after renal transplantation. These results suggest that while renal transplantation seems to have some beneficial outcomes, it is not sufficient to eradicate the hypertension in PKD patients.

\section{Concluding Remarks}

Primary cilium dysfunction has been associated with PKD, and primary cilia have also been proposed to regulate blood pressure. We believe that because our knowledge on cilia biology is still relatively limited compared to other organelles within a cell, there are certainly many more questions than answers that we could provide at present. In order to better understand the relationship between cilia and pathogenesis of hypertension, we need to understand the physiological roles of cilia in more detail and in many other organ systems. For example, vascular endothelial cilia have recently been proposed to regulate cell division [105] and endothelial-tomesenchymal transition [106]. In addition, the presence of cilia in vascular smooth muscle cells has also been reported, and sensory polycystin-1 and polycystin- 2 complex is localized in these cilia $[107,108]$. Although their roles are not clear at present, the vascular cilia are positioned in such a way that they maintain a specific alignment with respect to the lumen of the artery. Further studies of the role of this alignment may be necessary to shed light on their possible functions with regard to vascular hypertension.

Whether or not dysfunction in primary cilia causes hypertension in $\mathrm{PKD}$, there is certainly much work remaining. We are on the verge of applying our concept and understanding of PKD to better clinical practice and patient outcomes. Nonetheless, early and effective treatments of hypertension are clinically very important to decrease the morbidity and mortality of patients with PKD.

\section{Acknowledgments}

Due to restricted space, the authors apologize to those whose work is not described in this paper. They are grateful for stimulating discussion about primary cilia and polycystic kidney disease given by physicians, research assistants, graduates, undergraduates, and pharmacy students in our laboratory. Work from our laboratory that is cited in this paper has been supported by Grants from the NIH (DK080640) and the NIH Recovery Act Funds. We are thankful to The University of Toledo research programs.

\section{References}

[1] L. S. Krimer, E. Christopher Muly III, G. V. Williams, and P. S. Goldman-Rakic, "Dopaminergic regulation of cerebral cortical microcirculation," Nature Neuroscience, vol. 1, no. 4, pp. 286-289, 1998.

[2] E. W. Taylor, D. Jordan, and J. H. Coote, "Central control of the cardiovascular and respiratory systems and their interactions in vertebrates," Physiological Reviews, vol. 79, no. 3, pp. 855-916, 1999.

[3] P. I. Korner, G. A. Head, E. Badoer, A. Bobik, and J. A. Angus, "Role of brain amine transmitters and some neuromodulators in blood pressure, heart rate, and baroreflex control," Journal of Cardiovascular Pharmacology, vol. 10, no. 12, pp. S26-S32, 1987.

[4] S. E. Luff, "Ultrastructure of sympathetic axons and their structural relationship with vascular smooth muscle," Anatomy and Embryology, vol. 193, no. 6, pp. 515-531, 1996.

[5] E. K. Sloan, J. P. Capitanio, and S. W. Cole, "Stress-induced remodeling of lymphoid innervation," Brain, Behavior, and Immunity, vol. 22, no. 1, pp. 15-21, 2008.

[6] H. W. M. Steinbusch, "Distribution of histaminergic neurons and fibers in rat brain. Comparison with noradrenergic and 
serotonergic innervation of the vestibular system," Acta OtoLaryngologica, no. 479, supplement, pp. 12-23, 1991.

[7] G. Greisen, "Autoregulation of cerebral blood flow in newborn babies," Early Human Development, vol. 81, no. 5, pp. 423-428, 2005.

[8] S. S. Bolz, S. Pieperhoff, C. De Wit, and U. Pohl, "Chronic increases in transmural pressure reduce NO-mediated dilations in isolated resistance arteries of the hamster," Acta Physiologica Scandinavica, vol. 168, no. 1, pp. 113-117, 2000.

[9] G. M. Rubanyi, "Ionic mechanisms involved in the flow- and pressure-sensor function of the endothelium," Zeitschrift fur Kardiologie, vol. 80, no. 7, pp. 91-94, 1991.

[10] B. E. Spurrell, T. V. Murphy, and M. A. Hill, "Intraluminal pressure stimulates MAPK phosphorylation in arterioles: temporal dissociation from myogenic contractile response," American Journal of Physiology, vol. 285, no. 4, pp. H1764H1773, 2003.

[11] J. A. Bevan, "Shear stress, the endothelium and the balance between flow-induced contraction and dilation in animals and man," International Journal of Microcirculation, vol. 17, no. 5, pp. 248-256, 1997.

[12] K. E. Pyke and M. E. Tschakovsky, "The relationship between shear stress and flow-mediated dilatation: implications for the assessment of endothelial function," Journal of Physiology, vol. 568, no. 2, pp. 357-369, 2005.

[13] O. T. Raitakari and D. S. Celermajer, "Flow-mediated dilatation," British Journal of Clinical Pharmacology, vol. 50, no. 5, pp. 397-404, 2000.

[14] S. Chien, "Mechanotransduction and endothelial cell homeostasis: the wisdom of the cell," American Journal of Physiology, vol. 292, no. 3, pp. H1209-H1224, 2007.

[15] S. Chien, "Effects of disturbed flow on endothelial cells," Annals of Biomedical Engineering, vol. 36, no. 4, pp. 554-562, 2008.

[16] W. A. Aboualaiwi, M. Takahashi, B. R. Mell et al., "Ciliary polycystin-2 is a mechanosensitive calcium channel involved in nitric oxide signaling cascades," Circulation Research, vol. 104, no. 7, pp. 860-869, 2009.

[17] P. S. Agutter, "Cell mechanics and stress: from molecular details to the "universal cell reaction" and hormesis," BioEssays, vol. 29, no. 4, pp. 324-333, 2007.

[18] T. D. Brown, "Techniques for mechanical stimulation of cells in vitro: a review," Journal of Biomechanics, vol. 33, no. 1, pp. 3-14, 2000.

[19] P. A. Janmey and C. A. McCulloch, "Cell mechanics: integrating cell responses to mechanical stimuli," Annual Review of Biomedical Engineering, vol. 9, pp. 1-34, 2007.

[20] T. P. Stossel, J. Condeelis, L. Cooley et al., "Filamins as integrators of cell mechanics and signalling," Nature Reviews Molecular Cell Biology, vol. 2, no. 2, pp. 138-145, 2001.

[21] S. M. Nauli, H. S. Haymour, W. A. AbouAlaiwi, S. T. Lo, and A. M. Nauli, "Primary cilia are mechanosensory organelles in vestibular tissues," in Mechanosensitivity and Mechanotransduction, chapter 14, 2011.

[22] S. Abdul-Majeed and S. M. Nauli, "Calcium-mediated mechanisms of cystic expansion,” Biochimica et Biophysica Acta. In press.

[23] W. A. AbouAlaiwi, S. T. Lo, and S. M. Nauli, "Primary cilia: highly sophisticated biological sensors," Sensors, vol. 9, no. 9, pp. 7003-7020, 2009.

[24] S. M. Nauli, Y. Kawanabe, J. J. Kaminski, W. J. Pearce, D. E. Ingber, and J. Zhou, "Endothelial cilia are fluid shear sensors that regulate calcium signaling and nitric oxide production through polycystin-1," Circulation, vol. 117, no. 9, pp. 11611171, 2008.

[25] B. C. Berk, M. A. Corson, T. E. Peterson, and H. Tseng, "Protein kinases as mediators of fluid shear stress stimulated signal transduction in endothelial cells: a hypothesis for calcium-dependent and calcium-independent events activated by flow," Journal of Biomechanics, vol. 28, no. 12, pp. 1439-1450, 1995.

[26] M. Félétou and P. M. Vanhoutte, "Endothelium-dependent hyperpolarizations: past beliefs and present facts," Annals of Medicine, vol. 39, no. 7, pp. 495-516, 2007.

[27] L. J. Ignarro, G. Cirino, A. Casini, and C. Napoli, "Nitric oxide as a signaling molecule in the vascular system: an overview," Journal of Cardiovascular Pharmacology, vol. 34, no. 6, pp. 879-886, 1999.

[28] M. Nakane, "Soluble guanylyl cyclase: physiological role as an NO receptor and the potential molecular target for therapeutic application," Clinical Chemistry and Laboratory Medicine, vol. 41, no. 7, pp. 865-870, 2003.

[29] V. B. Bystrevskaia, A. S. Antonov, and N. A. Perov, "Primary cilium in the endothelial cells of the human aorta," Doklady Akademii Nauk SSSR, vol. 297, no. 5, pp. 1233-1236, 1987.

[30] V. B. Bystrevskaya, V. V. Lichkun, A. S. Antonov, and N. A. Perov, "An ultrastructural study of centriolar complexes in adult and embryonic human aortic endothelial cells," Tissue and Cell, vol. 20, no. 4, pp. 493-503, 1988.

[31] M. D. Haust, "Endothelial cilia in human aortic atherosclerotic lesions," Virchows Archiv, vol. 410, no. 4, pp. 317-326, 1987.

[32] W. A. AbouAlaiwi, S. Ratnam, R. L. Booth, J. V. Shah, and S. M. Nauli, "Endothelial cells from humans and mice with polycystic kidney disease are characterized by polyploidy and chromosome segregation defects through survivin downregulation," Human Molecular Genetics, vol. 20, no. 2, pp. 354-367, 2011.

[33] C. Iomini, K. Tejada, W. Mo, H. Vaananen, and G. Piperno, "Primary cilia of human endothelial cells disassemble under laminar shear stress," Journal of Cell Biology, vol. 164, no. 6, pp. 811-817, 2004.

[34] S. P. Collin and H. B. Collin, "Primary cilia in vertebrate corneal endothelial cells," Cell Biology International, vol. 28, no. 2, pp. 125-130, 2004.

[35] M. J. Doughty, "Changes in cell surface primary cilia and microvilli concurrent with measurements of fluid flow across the rabbit corneal endothelium ex vivo," Tissue and Cell, vol. 30, no. 6, pp. 634-643, 1998.

[36] B. C. Gallagher, "Primary cilia of the corneal endothelium," American Journal of Anatomy, vol. 159, no. 4, pp. 475-484, 1980.

[37] M. Kojimahara, "Endothelial cilia in rat mesenteric arteries and intramyocardial capillaries," Zeitschrift fur Mikroskopisch-Anatomische Forschung, vol. 104, no. 3, pp. 412-416, 1990.

[38] K. Van der Heiden, B. P. Hierck, R. Krams et al., "Endothelial primary cilia in areas of disturbed flow are at the base of atherosclerosis," Atherosclerosis, vol. 196, no. 2, pp. 542-550, 2008.

[39] V. Chauvet, F. Qian, N. Boute et al., "Expression of PKD1 and PKD2 transcripts and proteins in human embryo and during normal kidney development," American Journal of Pathology, vol. 160, no. 3, pp. 973-983, 2002. 
[40] M. A. Garcia-Gonzalez, P. Outeda, Q. Zhou et al., "Pkd1 and $\mathrm{Pkd} 2$ are required for normal placental development," PLoS ONE, vol. 5, no. 9, pp. 1-12, 2010.

[41] O. Ibraghimov-Beskrovnaya, W. R. Dackowski, L. Foggensteineri et al., "Polycystin: in vitro synthesis, in vivo tissue expression, and subcellular localization identifies a large membrane-associated protein," Proceedings of the National Academy of Sciences of the United States of America, vol. 94, no. 12, pp. 6397-6402, 1997.

[42] A. C. Ong, P. C. Harris, S. Biddolph, C. Bowker, and C. J. Ward, "Characterisation and expression of the PKD-1 protein, polycystin, in renal and extrarenal tissues," Kidney International, vol. 55, no. 5, pp. 2091-2116, 1999.

[43] A. R. Pries and T. W. Secomb, "Control of blood vessel structure: insights from theoretical models," American Journal of Physiology, vol. 288, no. 3, pp. H1010-H1015, 2005.

[44] V. E. Torres, "Role of vasopressin antagonists," Clinical Journal of the American Society of Nephrology, vol. 3, no. 4, pp. 1212-1218, 2008.

[45] A. R. Pries, T. W. Secomb, and P. Gaehtgens, "Structural autoregulation of terminal vascular beds: vascular adaptation and development of hypertension," Hypertension, vol. 33, no. 1 I, pp. 153-161, 1999.

[46] R. K. Shields, "Muscular, skeletal, and neural adaptations following spinal cord injury," Journal of Orthopaedic and Sports Physical Therapy, vol. 32, no. 2, pp. 65-74, 2002.

[47] R. E. Poelmann, K. Van Der Heiden, A. Gittenberger-De Groot, and B. P. Hierck, "Deciphering the endothelial shear stress sensor," Circulation, vol. 117, no. 9, pp. 1124-1126, 2008.

[48] K. Van Der Heiden, B. C. W. Groenendijk, B. P. Hierck et al., "Monocilia on chicken embryonic endocardium in low shear stress areas," Developmental Dynamics, vol. 235, no. 1, pp. 1928,2006

[49] J. M. Tarbell and M. Y. Pahakis, "Mechanotransduction and the glycocalyx," Journal of Internal Medicine, vol. 259, no. 4, pp. 339-350, 2006.

[50] S. Weinbaum, J. M. Tarbell, and E. R. Damiano, "The structure and function of the endothelial glycocalyx layer," Annual Review of Biomedical Engineering, vol. 9, pp. 121-167, 2007.

[51] R. J. Kolb and S. M. Nauli, "Ciliary dysfunction in polycystic kidney disease: an emerging model with polarizing potential," Frontiers in Bioscience, vol. 13, no. 12, pp. 4451-4466, 2008.

[52] S. M. Nauli, F. J. Alenghat, Y. Luo et al., "Polycystins 1 and 2 mediate mechanosensation in the primary cilium of kidney cells," Nature Genetics, vol. 33, no. 2, pp. 129-137, 2003.

[53] G. M. Fick, A. M. Johnson, W. S. Hammond, and P. A. Gabow, "Causes of death in autosomal dominant polycystic kidney disease," Journal of the American Society of Nephrology, vol. 5, no. 12, pp. 2048-2056, 1995.

[54] L. M. Guay-Woodford, "Renal cystic diseases: diverse phenotypes converge on the cilium/centrosome complex," Pediatric Nephrology, vol. 21, no. 10, pp. 1369-1376, 2006.

[55] M. I. Lilova and D. L. Petkov, "Intracranial aneurysms in a child with autosomal recessive polycystic kidney disease," Pediatric Nephrology, vol. 16, no. 12, pp. 1030-1032, 2001.

[56] T. Ecder and R. W. Schrier, "Cardiovascular abnormalities in autosomal-dominant polycystic kidney disease," Nature Reviews Nephrology, vol. 5, no. 4, pp. 221-228, 2009.

[57] R. D. Perrone, "Extrarenal manifestations of ADPKD," Kidney International, vol. 51, no. 6, pp. 2022-2036, 1997.

[58] G. M. Fick-Brosnahan, Z. Vu Tran, A. M. Johnson, J. D. Strain, and P. A. Gabow, "Progression of autosomal-domi- nant polycystic kidney disease in children," Kidney International, vol. 59, no. 5, pp. 1654-1662, 2001.

[59] P. A. Gabow, A. B. Chapman, A. M. Johnson et al., "Renal structure and hypertension in autosomal dominant polycystic kidney disease," Kidney International, vol. 38, no. 6, pp. 1177-1180, 1990.

[60] A. Gonzalo, A. Gallego, M. Rivera, L. Orte, and J. Ortuño, "Influence of hypertension on early renal insufficiency in autosomal dominant polycystic kidney disease," Nephron, vol. 72, no. 2, pp. 225-230, 1996.

[61] C. L. Kelleher, K. K. McFann, A. M. Johnson, and R. W. Schrier, "Characteristics of hypertension in young adults with autosomal dominant polycystic kidney disease compared with the general U.S. population," American Journal of Hypertension, vol. 17, no. 11, pp. 1029-1034, 2004.

[62] R. W. Schrier, A. M. Johnson, K. McFann, and A. B. Chapman, "The role of parental hypertension in the frequency and age of diagnosis of hypertension in offspring with autosomaldominant polycystic kidney disease," Kidney International, vol. 64, no. 5, pp. 1792-1799, 2003.

[63] A. Sedman, P. Bell, and M. Manco-Johnson, "Autosomal dominant polycystic kidney disease in childhood: a longitudinal study," Kidney International, vol. 31, no. 4, pp. 10001005, 1987.

[64] G. M. Fick, I. T. Duley, A. M. Johnson, J. D. Strain, M. L. Manco-Johnson, and P. A. Gabow, "The spectrum of autosomal dominant polycystic kidney disease in children," Journal of the American Society of Nephrology, vol. 4, no. 9, pp. 16541660, 1994.

[65] D. D. Ivy, E. M. Shaffer, A. M. Johnson, W. J. Kimberling, A. Dobin, and P. A. Gabow, "Cardiovascular abnormalities in children with autosomal dominant polycystic kidney disease," Journal of the American Society of Nephrology, vol. 5, no. 12, pp. 2032-2036, 1995.

[66] A. Shamshirsaz, R. M. Bekheirnia, M. Kamgar et al., "Autosomal-dominant polycystic kidney disease in infancy and childhood: progression and outcome," Kidney International, vol. 68, no. 5, pp. 2218-2224, 2005.

[67] A. B. Chapman and R. W. Schrier, "Pathogenesis of hypertension in autosomal dominant polycystic kidney disease," Seminars in Nephrology, vol. 11, no. 6, pp. 653-660, 1991.

[68] T. Ecder and R. W. Schrier, "Hypertension in autosomaldominant polycystic kidney disease: early occurrence and unique aspects," Journal of the American Society of Nephrology, vol. 12, no. 1, pp. 194-200, 2001.

[69] P. Clausen, B. Feldt-Rasmussen, J. Iversen, M. Lange, I. Eidemak, and S. Strandgaard, "Flow-associated dilatory capacity of the brachial artery is intact in early autosomal dominant polycystic kidney disease," American Journal of Nephrology, vol. 26, no. 4, pp. 335-339, 2006.

[70] D. Wang, S. Strandgaard, M. L. Borresen et al., "Asymmetric dimethylarginine and lipid peroxidation products in early autosomal dominant polycystic kidney disease," American Journal of Kidney Diseases, vol. 51, no. 2, pp. 184-191, 2008.

[71] D. Wang, J. Iversen, and S. Strandgaard, "Endotheliumdependent relaxation of small resistance vessels is impaired in patients with autosomal dominant polycystic kidney disease," Journal of the American Society of Nephrology, vol. 11, no. 8, pp. 1371-1376, 2000.

[72] D. Wang, J. Iversen, C. S. Wilcox, and S. Strandgaard, "Endothelial dysfunction and reduced nitric oxide in resistance arteries in autosomal-dominant polycystic kidney disease," Kidney International, vol. 64, no. 4, pp. 1381-1388, 2003. 
[73] D. Wang and S. Strandgaard, "The pathogenesis of hypertension in autosomal dominant polycystic kidney disease," Journal of Hypertension, vol. 15, no. 9, pp. 925-933, 1997.

[74] M. A. Al-Nimri, R. Komers, T. T. Oyama, A. R. Subramanya, J. N. Lindsley, and S. Anderson, "Endothelial-derived vasoactive mediators in polycystic kidney disease," Kidney International, vol. 63, no. 5, pp. 1776-1784, 2003.

[75] M. Merta, J. Reiterová, R. Ryšavá et al., "Role of endothelin and nitric oxide in the pathogenesis of arterial hypertension in autosomal dominant polycystic kidney disease," Physiological Research, vol. 52, no. 4, pp. 433-437, 2003.

[76] A. B. Chapman, A. Johnson, P. A. Gabow, and R. W. Schrier, "The renin-angiotensin-aldosterone system and autosomal dominant polycystic kidney disease," New England Journal of Medicine, vol. 323, no. 16, pp. 1091-1096, 1990.

[77] T. Ecder, A. B. Chapman, G. M. Brosnahan, C. L. Edelstein, A. M. Johnson, and R. W. Schrier, "Effect of antihypertensive therapy on renal function and urinary albumin excretion in hypertensive patients with autosomal dominant polycystic kidney disease," American Journal of Kidney Diseases, vol. 35, no. 3, pp. 427-432, 2000.

[78] P. C. Graham and G. B. M. Lindop, "The anatomy of the renin-secreting cell in adult polycystic kidney disease," Kidney International, vol. 33, no. 6, pp. 1084-1090, 1988.

[79] D. S. Keith, V. E. Torres, C. M. Johnson, and K. E. Holley, "Effect of sodium chloride, enalapril, and losartan on the development of polycystic kidney disease in Han:SPRD rats," American Journal of Kidney Diseases, vol. 24, no. 3, pp. 491498, 1994.

[80] R. Schrier, K. McFann, A. Johnson et al., "Cardiac and renal effects of standard versus rigorous blood pressure control in autosomal-dominant polycystic kidney disease: results of a seven-year prospective randomized study," Journal of the American Society of Nephrology, vol. 13, no. 7, pp. 1733-1739, 2002.

[81] A. Ramunni, A. Saracino, T. Esposito, M. T. Saliani, and P. Coratelli, "Renal vascular resistance and renin-angiotensin system in the pathogenesis of early hypertension in autosomal dominant polycystic kidney disease," Hypertension Research, vol. 27, no. 4, pp. 221-225, 2004.

[82] J. Kaspareit-Rittinghausen, F. Deerberg, K. G. Rapp, and A. Wcislo, "Renal hypertension in rats with hereditary polycystic kidney disease," Zeitschrift fur Versuchstierkunde, vol. 33, no. 5, pp. 201-204, 1990.

[83] J. L. Lavoie, K. D. Lake-Bruse, and C. D. Sigmund, "Increased blood pressure in transgenic mice expressing both human renin and angiotensinogen in the renal proximal tubule," American Journal of Physiology, vol. 286, no. 5, pp. F965F971, 2004.

[84] A. B. Chapman and P. A. Gabow, "Hypertension in autosomal dominant polycystic kidney disease," Kidney International, vol. 51, no. 61, supplement, pp. S71-S73, 1997.

[85] E. A. Mcpherson, Z. Luo, R. A. Brown et al., "Chymaselike angiotensin II-generating activity in end-stage human autosomal dominant polycystic kidney disease," Journal of the American Society of Nephrology, vol. 15, no. 2, pp. 493-500, 2004.

[86] P. J. Azurmendi, A. R. Fraga, F. M. Galan et al., "Early renal and vascular changes in ADPKD patients with low-grade albumin excretion and normal renal function," Nephrology Dialysis Transplantation, vol. 24, no. 8, pp. 2458-2463, 2009.

[87] C. T. Itty, A. Farshid, and G. Talaulikar, "Spontaneous coronary artery dissection in a woman with polycystic kidney disease," American Journal of Kidney Diseases, vol. 53, no. 3, pp. 518-521, 2009.
[88] S. Rong, X. Jin, C. Ye, J. Chen, and C. Mei, "Carotid vascular remodelling in patients with autosomal dominant polycystic kidney disease," Nephrology, vol. 14, no. 1, pp. 113-117, 2009.

[89] M. Sawicki, A. Walecka, J. Rozanski, K. Safranow, and K. Ciechanowski, "Doppler sonography measurements of renal vascular resistance in autosomal-dominant polycystic kidney disease," Medical Science Monitor, vol. 15, no. 8, pp. MT101MT104, 2009.

[90] K. Turkmen, H. Oflaz, B. Uslu et al., "Coronary flow velocity reserve and carotid intima media thickness in patients with autosomal dominant polycystic kidney disease: from impaired tubules to impaired carotid and coronary arteries," Clinical Journal of the American Society of Nephrology, vol. 3, no. 4, pp. 986-991, 2008.

[91] M. A. Arnaout, "Molecular genetics and pathogenesis of autosomal dominant polycystic kidney disease," Annual Review of Medicine, vol. 52, pp. 93-123, 2001.

[92] C. Boulter, S. Mulroy, S. Webb, S. Fleming, K. Brindle, and R. Sandford, "Cardiovascular, skeletal, and renal defects in mice with a targeted disruption of the Pkd1 gene," Proceedings of the National Academy of Sciences of the United States of America, vol. 98, no. 21, pp. 12174-12179, 2001.

[93] K. Kim, I. Drummond, O. Ibraghimov-Beskrovnaya, K. Klinger, and M. A. Arnaout, "Polycystin 1 is required for the structural integrity of blood vessels," Proceedings of the National Academy of Sciences of the United States of America, vol. 97, no. 4, pp. 1731-1736, 2000.

[94] S. Muto, A. Aiba, Y. Saito et al., "Pioglitazone improves the phenotype and molecular defects of a targeted Pkd1 mutant," Human Molecular Genetics, vol. 11, no. 15, pp. 1731-1742, 2002.

[95] G. Wu, G. S. Markowitz, L. Li et al., "Cardiac defects and renal failure in mice with targeted mutations in $\mathrm{Pkd} 2$," Nature Genetics, vol. 24, no. 1, pp. 75-78, 2000.

[96] I. H. H. T. Klein, G. Ligtenberg, P. L. Oey, H. A. Koomans, and P. J. Blankestijn, "Sympathetic activity is increased in polycystic kidney disease and is associated with hypertension," Journal of the American Society of Nephrology, vol. 12, no. 11, pp. 2427-2433, 2001.

[97] J. Neumann, G. Ligtenberg, I. H. H. T. Klein, and P. J. Blankestijn, "Pathogenesis and treatment of hypertension in polycystic kidney disease," Current Opinion in Nephrology and Hypertension, vol. 11, no. 5, pp. 517-521, 2002.

[98] R. Zeltner, R. Poliak, B. Stiasny, R. E. Schmieder, and B. D. Schulze, "Renal and cardiac effects of antihypertensive treatment with ramipril vs metoprolol in autosomal dominant polycystic kidney disease," Nephrology Dialysis Transplantation, vol. 23, no. 2, pp. 573-579, 2008.

[99] A. Masoumi, B. Reed-Gitomer, C. Kelleher, M. R. Bekheirnia, and R. W. Schrier, "Developments in the management of autosomal dominant polycystic kidney disease," Therapeutics and Clinical Risk Management, vol. 4, no. 2, pp. 393-407, 2008.

[100] G. Mancia, R. Dell'Oro, F. Quarti-Trevano, F. Scopelliti, and G. Grassi, "Angiotensin-sympathetic system interactions in cardiovascular and metabolic disease," Journal of Hypertension, vol. 24, no. 1, pp. S51-S56, 2006.

[101] A. H. Van Den Meiracker and F. Boomsma, "The angiotensin II-sympathetic nervous system connection," Journal of $\mathrm{Hy}$ pertension, vol. 21, no. 8, pp. 1453-1454, 2003.

[102] V. H. Gattone II, T. M. Siqueira Jr., C. R. Powell, C. M. Trambaugh, J. E. Lingeman, and A. L. Shalhav, "Contribution of renal innervation to hypertension in rat autosomal dominant polycystic kidney disease," Experimental Biology and Medicine, vol. 233, no. 8, pp. 952-957, 2008. 
[103] K. W. Florijn, P. C. Chang, F. J. Van der Woude, J. H. Van Bockel, and J. L. C. M. Van Saase, "Long-term cardiovascular morbidity and mortality in autosomal dominant polycystic kidney disease patients after renal transplantation," Transplantation, vol. 57, no. 1, pp. 73-81, 1994.

[104] Y. Shiroyanagi, K. Tanabe, Y. Hashimoto et al., "Kidney transplantation in the recipient with autosomal-dominant polycystic kidney disease: a single center experience," Transplantation Proceedings, vol. 32, no. 7, pp. 1841-1843, 2000.

[105] W. A. AbouAlaiwi, S. Ratnam, R. L. Booth, J. V. Shah, and S. M. Nauli, "Endothelial cells from humans and mice with polycystic kidney disease are characterized by polyploidy and chromosome segregation defects through survivin downregulation," Human Molecular Genetics, vol. 20, no. 2, pp. 354-367, 2011.

[106] A. D. Egorova, P. P. Khedoe, M.-J. Goumans et al., "Lack of primary cilia primes shear-induced endothelial-tomesenchymal transition," Circulation Research, vol. 108, no. 9, pp. 1093-1101, 2011.

[107] C. J. Lu, H. Du, J. Wu et al., "Non-random distribution and sensory functions of primary cilia in vascular smooth muscle cells," Kidney and Blood Pressure Research, vol. 31, no. 3, pp. 171-184, 2008.

[108] J. Wu, H. Du, X. Wang, C. Mei, G. C. Sieck, and Q. Qian, "Characterization of primary cilia in human airway smooth muscle cells,” Chest, vol. 136, no. 2, pp. 561-570, 2009. 


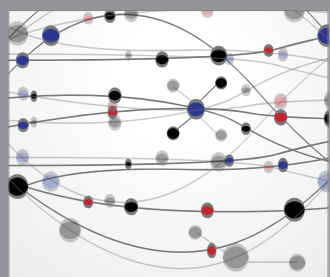

The Scientific World Journal
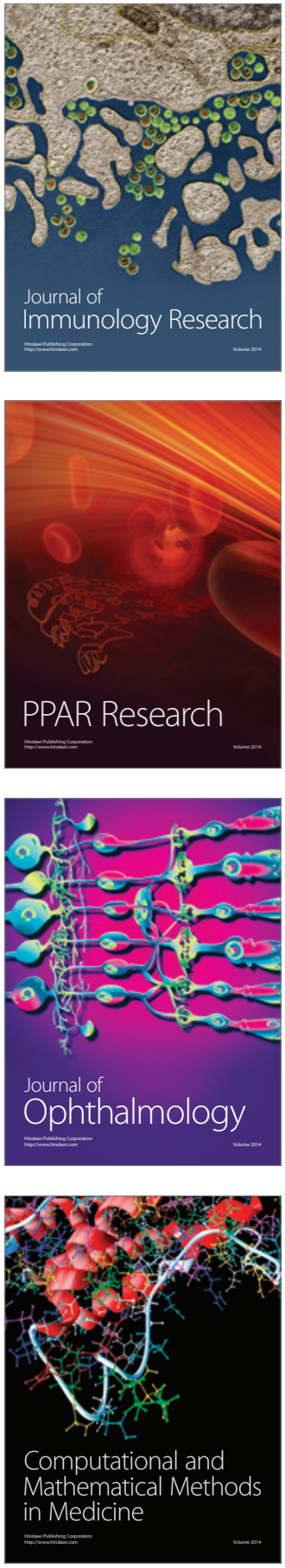

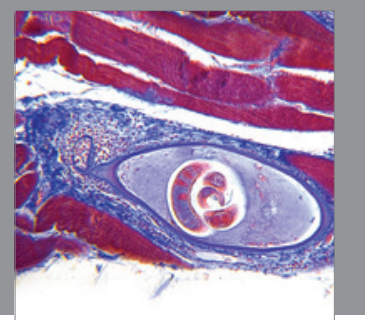

Gastroenterology

Research and Practice
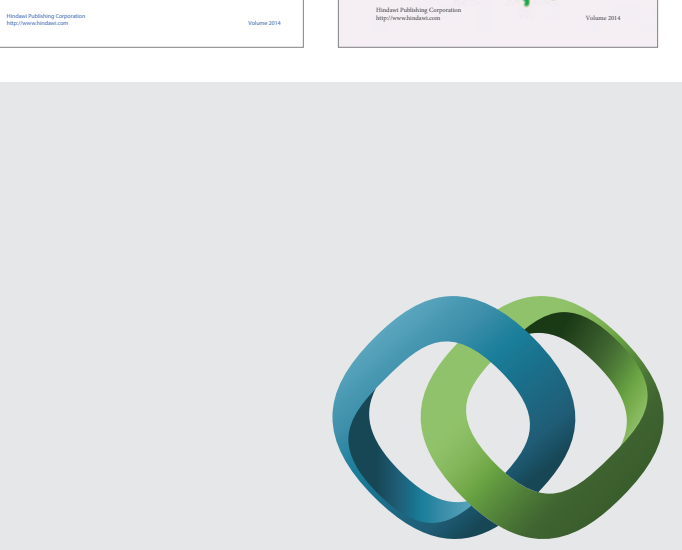

\section{Hindawi}

Submit your manuscripts at

http://www.hindawi.com
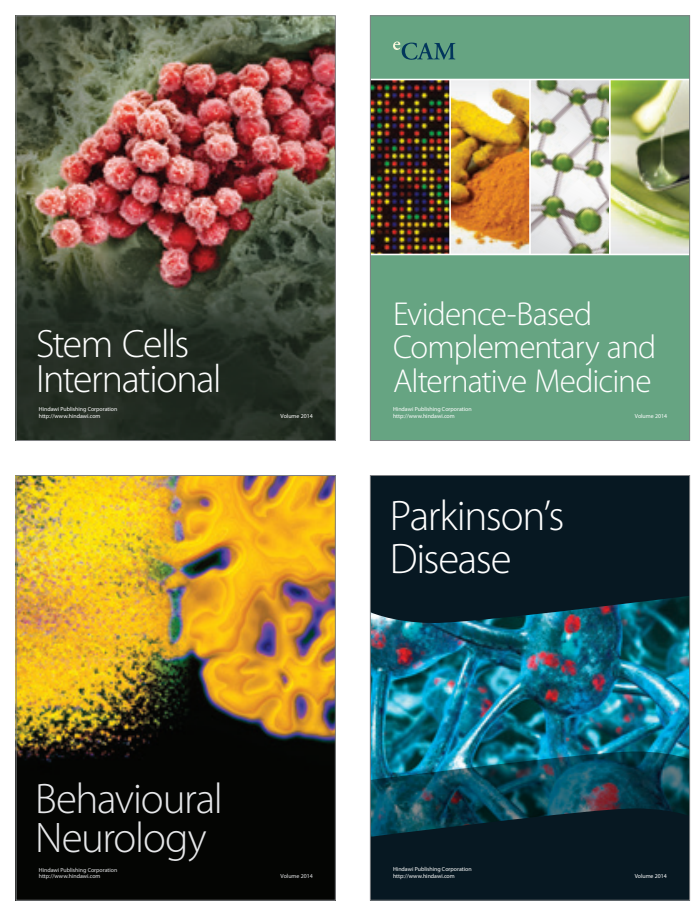

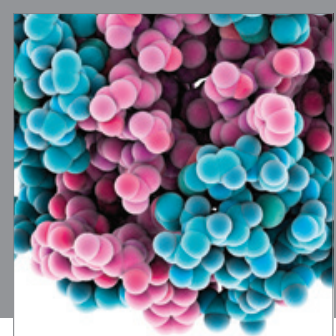

Journal of
Diabetes Research

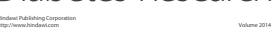

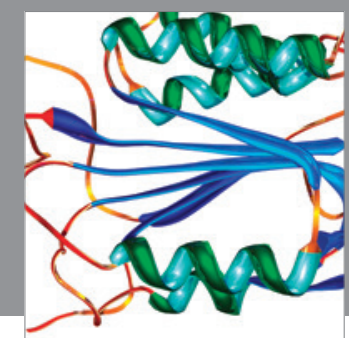

Disease Markers
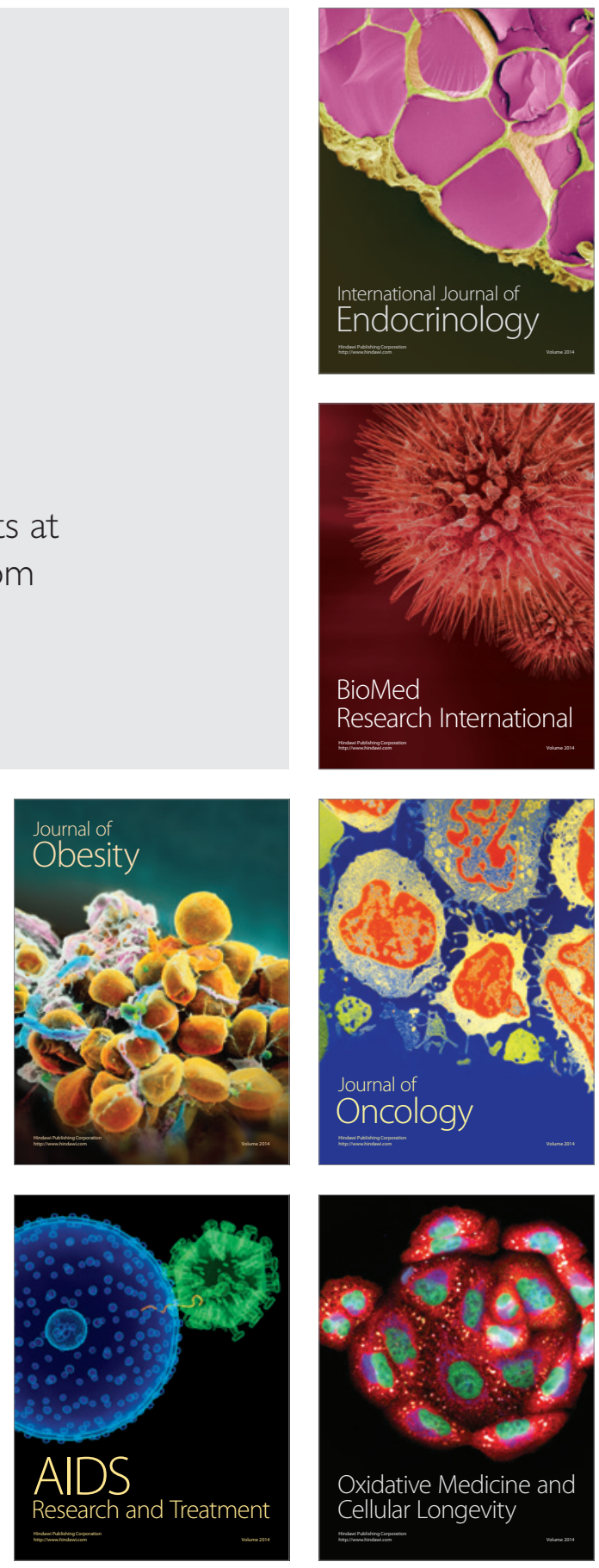